\title{
Parkinson's Disease-Related Motor and Nonmotor Symptoms in the Lancaster Amish
}

\author{
Michael D.F. Goldenberg ${ }^{a} \quad$ Xuemei Huang $^{\mathrm{a}}$ Honglei Chen $^{\mathrm{b}}$ Lan Kong ${ }^{\mathrm{c}}$ \\ Teodor T. Postolache ${ }^{d, e, f}$ John W. Stiller ${ }^{d, g}$ Katherine A. Ryan ${ }^{f}$ Mary Pavlovich $^{\text {h }}$ \\ Toni I. Pollin ${ }^{h}$ Alan R. Shuldiner ${ }^{h}$ Richard B. Mailman ${ }^{a}, i$ Braxton D. Mitchell ${ }^{h, j}$ \\ ${ }^{a}$ Department of Neurology, Penn State Health-Milton S. Hershey Medical Center, Hershey, PA, USA; bepartment of \\ Epidemiology, Michigan State University, East Lansing, MI, USA; 'Department of Public Health Sciences, Penn State University- \\ Milton S. Hershey Medical Center, Hershey, PA, USA; 'Mood and Anxiety Program, University of Maryland School of Medicine, \\ Baltimore, MD, Rocky Mountain Mental Illness, Research Education and Clinical Center, Denver, CO, USA; ${ }^{e}$ Rocky Mountain \\ Mental IIIness Research, Education and Clinical Center, Denver, CO, USA; ${ }^{f}$ VISN 5 Capitol Health Care Network Mental IIIness \\ Research Education and Clinical Center, Baltimore, MD, USA; 9 St. Elizabeth's Hospital, Neurology Consultation Service, \\ Washington, DC, USA; hProgram for Personalized and Genomic Medicine, Division of Endocrinology, Diabetes and Nutrition, \\ Department of Medicine, University of Maryland School of Medicine, Baltimore, MD, USA; 'Department of Pharmacology, \\ Penn State College of Medicine, Hershey, PA, USA; 'ंGeriatric Research and Education Clinical Center, Veterans Administration \\ Medical Center, Baltimore, MD, USA
}

\section{Keywords}

Parkinson's disease · Parkinsonism · Amish · Nonmotor symptoms

\begin{abstract}
Introduction: Previous research has suggested that the Amish may experience a relatively high prevalence of Parkinson's disease (PD) and/or parkinsonian motor signs. Methods: In a large sample from the Amish community in Lancaster County, Pennsylvania, age $\geq 18$ years, we assessed the prevalence of self-reported PD diagnosis. For those without self-reported PD diagnosis, we assessed the frequency of PDrelated motor symptoms using a 9-item questionnaire that was designed by the PD Epidemiology Research Group. Lastly, we queried study participants for the presence of 2 nonmotor symptoms that have been commonly linked to PD: bowel movement frequency and daytime sleepiness. $\boldsymbol{R e}$ -
\end{abstract}

sults: Among 2,025 subjects who answered the PD questionnaire, 430 were older than 60 years. Of 430 participants $\geq 60$ years, 5 (1.2\%) reported a PD diagnosis. Of those without a PD diagnosis, $10.5 \%$ reported $\geq 1$ and $1.2 \% \geq 4$ motor symptoms for the 9-item PD screening questionnaire. Of the 3,789 subjects who answered the question about bowel movement frequency, $0.7 \%$ reported $\leq 3$ bowel movements per week. Among 1,710 subjects who answered the question about daytime sleepiness, $8.1 \%$ of the participants reported "always" sleepy during the day. Discussion: These data neither support a markedly higher PD prevalence in the older Lancaster Amish nor do they show dramatically higher motor and/or selected nonmotor symptoms than the general population. Future studies that employ more rigorous procedures for case identification and PD-specific preclinical symptoms/tests are needed to determine the potential differences and similarities among different Amish populations and between Amish and non-Amish populations.

(c) 2020 S. Karger AG, Basel

Xuemei Huang

Department of Neurology, Penn State Hershey Medical Center

500 University Dr., H-037

Hershey 17033-0850 (USA)

xuemei@psu.edu 


\section{Introduction}

Parkinson's disease (PD) is marked clinically by motor disability and pathologically by nigrostriatal dopaminergic neuronal loss, but also by extensive nonmotor involvement and extensive extranigral pathology [1]. The exact etiology for the disease is unknown and probably is related to the complex interaction among genetic, environmental and lifestyle factors. Several hundred Amish immigrated to the US in the 1700s [2]. The communities are characterized by large family sizes and social cohesiveness. Since Amish marry within their religion, they represent a genetic isolate [3] and may assist in understanding the genetic contributions to PD [4-6]. In addition, Amish communities generally follow an agriculturebased lifestyle and experience low rates of smoking, factors known to be associated with increased risk for PD.

In a community-based survey of 4,369 Amish in Missouri, Racette et al. [7] reported that 7\% of 213 participants older than 60 years met the criteria of clinical diagnosis of PD. The prevalence is substantially higher than the $\sim 1 \%$ generally reported for older adult populations $[8,9]$ and "nearly 10 -fold greater compared with a previous American door-to-door study" [7, 10]. This suggested that the Amish population might be useful in studying novel risk factors for PD.

Because the Amish communities founded in Pennsylvania, Ohio/Indiana, Illinois, and Missouri represent distinct population isolates, we tested if the Lancaster County, PA Amish population also had this markedly higher prevalence of PD symptoms. Because nonmotor symptoms, such as constipation and sleep disorders, are now known to be integral part of PD [11] and often occur prior to the onset of typical motor symptoms $[12,13]$, we also ascertained the prevalence of these nonmotor symptoms.

\section{Materials and Methods}

\section{Amish Wellness Study}

Lancaster County, PA, is home to 35,000 Old Order Amish (OOA) individuals, of whom approximately one-half are older than 21 years. In 2010, we initiated the Amish Wellness Study to ascertain the entire adult OOA population of Lancaster County for health assessment and biobanking for future studies. The study was performed either at the Amish Research Clinic in Lancaster, $\mathrm{PA}$, or in an RV repurposed for performing field-based clinical research in the community. All Amish in Lancaster County aged 18 years and older were eligible for enrollment. Recruitment was carried out by geographic area, with nurses and liaisons going house-to-house with invitations to participate. Individuals agree-

PD and Nonmotor Symptoms in Lancaster Amish ing to participate signed a consent were scheduled for a study visit. In the visit, a nurse well known to the Amish administered the wellness evaluation.

This report is based on up to 3,789 participants who were administered a medical history questionnaire by the research nurse between January 2010 and February 2016 [14]. Although some of the PD-related questions were included at the inception of the Wellness Study, others, as indicated below, were added in subsequent years. The Amish Wellness Study was approved by the University of Maryland Institutional Review Board, and all procedures were done in accord with the Helsinki Declaration of 1975.

\section{Assessment Tools}

Assessment of PD-Related Motor Symptoms

In 2012, we expanded the medical history questionnaire used in the Amish Wellness Study to ascertain prior diagnosis of PD, adding the following question: "Have you ever been diagnosed by a physician as having PD?" If the answer was "yes," it was recorded as a prevalent PD case. If the answer was "no," we then continued by administering a 9-item questionnaire (see online suppl. Table 1; for all online suppl.material, seewww.karger.com/doi/10.1159/000509394) that was designed by the PD Epidemiology Research Group [15] to provide the first stage of a door-to-door survey for PD.

Assessment of PD-Related Nonmotor Symptoms

We queried study participants by questionnaire for the presence of 2 nonmotor symptoms that have been commonly linked to PD: bowel movement frequency and daytime sleepiness.

\section{Bowel Movement Frequency}

Study participants were asked the following question: "How many times a week do you usually have a bowel movement?" We considered $\leq 3$ bowel movements per week to be 'infrequent', a definition close to that used in the Health Professionals and Nurses' Health studies [16], the same definition was also used to study constipation as a PD prodromal symptom in the general population in one of our previous reports [17].

\section{Daytime Sleepiness}

Study participants were asked the following question: "How often did you feel excessively or overly sleepy during the day?" Allowable responses were "never," "rarely (<1/week)," "sometimes (1-2/week)," "frequent" (3-4/week)," and "always (5-7/week)." We defined daytime sleepiness as "always" sleepy during the day, similar to the definition of daytime sleepiness used in the Honolulu Asia Aging Study (“Are you sleepy most of the day?"), which shows a significant correlation with PD risk $(\mathrm{OR}=3.3)$ [18]. In addition, a similar cutoff was used to study daytime sleepiness in the general population in our previous report [17].

\section{Statistical Analysis}

We computed the prevalence (and 95\% confidence intervals [CIs]) of all symptoms by age group and gender. For motor symptoms, we calculated the prevalence of reporting 1,2, and 3 or more symptoms. For nonmotor symptoms, we calculated the prevalence of those with $\leq 3$ bowel movements per week and those reported "always" sleepy during the day, the same definition used by our group to define "constipation" and "excessive daytime sleepiness" in the US National Health and Nutrition Examination Surveys (NHANES) [17]. 
Table 1. The proportion of Amish men and women reporting $\geq 1,2,3,4$, or 5 motor symptoms according to age

\begin{tabular}{lllllll}
\hline Age group, years & $18-29$ & $30-39$ & $40-49$ & $50-59$ & $60-69$ & $\geq 70$ \\
Participants, $n$ & 489 & 468 & 346 & 300 & 226 & 204 \\
Males/females, $n$ & $170 / 319$ & $212 / 256$ & $160 / 186$ & $123 / 177$ & $112 / 114$ & $89 / 115$ \\
Motor symptoms (males), \% & & & & & & \\
$\quad \geq 1$ & 1.2 & 0.5 & 0.6 & 0.8 & 2.7 & 19.1 \\
$\quad \geq 2$ & 0.0 & 0.0 & 0.6 & 0.0 & 1.8 & 10.1 \\
$\geq 3$ & 0.0 & 0.0 & 0.0 & 0.0 & 0.9 & 7.9 \\
$\geq 4$ & 0.0 & 0.0 & 0.0 & 0.0 & 0.0 & 1.1 \\
$\geq 5$ & 0.0 & 0.0 & 0.0 & 0.0 & 0.0 & 1.1 \\
Motor symptoms (females), \% & $18-29$ yr & $30-39 \mathrm{yr}$ & $40-49 \mathrm{yr}$ & $50-59 \mathrm{yr}$ & $60-69 \mathrm{yr}$ & $\geq 70 \mathrm{yr}$ \\
$\geq 1$ & 0.3 & 0.0 & 0.5 & 1.1 & 2.6 & 19.1 \\
$\geq 2$ & 0.0 & 0.0 & 0.0 & 0.6 & 0.9 & 9.6 \\
$\geq 3$ & 0.0 & 0.0 & 0.0 & 0.6 & 0.9 & 4.4 \\
$\geq 4$ & 0.0 & 0.0 & 0.0 & 0.0 & 0.9 & 2.6 \\
$\geq 5$ & 0.0 & 0.0 & 0.0 & 0.0 & 0.0 & 2.6 \\
\hline
\end{tabular}

\section{Results}

This report is based on questionnaire responses obtained from 3,789 Amish individuals, of whom 1,076 (28\%) were $\geq 60$ years old and 2,132 (56\%) were women. Because the Amish Wellness Study questionnaires evolved over time, the constipation question was administered to all 3,789 subjects, the PD symptom questionnaire to 2,025 subjects, and the daytime sleepiness question to only 1,710 subjects.

Among 2,025 subjects who answered the PD questionnaire, 430 were older than 60 years. Five subjects reported having a PD diagnosis, all of whom were $\geq 70$ years old, yielding a prevalence of $1.2 \%$ for those $\geq 60$ (95\% CI: $0.4-2.7 \%$ ) and $2.5 \%$ for those $\geq 70$ years old (95\% CI: $0.8-5.6 \%$ ), respectively. Four of these were women. The overall frequency of motor symptoms was very low for subjects younger than 60 (any symptom $<1 \%$ ), dramatically increasing after the age of 60 with $10.5 \%$ reporting "yes" $\geq 1,5.5 \% \geq 2,3.2 \% \geq 3$, and $1.2 \% \geq 4$ items based on the 9-item PD screening questionnaire, respectively (Table 1; online suppl. Fig. 1). The overall frequency of motor symptoms was highest in those $\geq 70$ years old, of whom $19.1 \%$ reported "yes" on at least one item (Table 1). Among 204 participants $\geq 70$ years old, poor balance was the most commonly reported symptom $(n=19)$, followed by trouble rising from a chair $(n=16)$ and shakes and trouble with buttons ( $n=10$ for each). The prevalence of motor symptoms was similar between males and females, although women were more likely to report poor balance (14/115) and trouble rising from a chair (10/115).
The overall prevalence of low bowel movement frequency ( $\leq 3 /$ week) was $0.75 \%$ (95\% CI: $0.47-1.01 \%$ ), only slightly higher after age 60 in both men and women. The frequency of reporting daytime sleepiness was 8.1\% (95\% CI: $6.78-9.36 \%)$. Figure 1 details the age- and genderstratified prevalence for constipation and excessive sleepiness we found, using our data for the US population as reference (dashed-lines) [17].

\section{Discussion}

In this pilot study, we estimated the prevalence of $\mathrm{PD}$ diagnosis and symptoms in the Lancaster Amish population in Pennsylvania, aiming to confirm whether PD is more prevalent in Amish people as a study reported previously. In our study, $1.2 \%$ of older Lancaster Amish $\geq 60$ years and $2.4 \%$ for those $\geq 70$ years reported a PD diagnosis. These estimates are lower than those reported in the Missouri Amish (5.8\% for those $\geq 60$ and 10\% for those $\geq 70$ years) [7], but similar to those estimated in a cosmopolitan area of a neighboring state $(1.7 \%$ for those $\geq 65$ years) [19]. Although differences in case ascertainment and definition (e.g., history of physician diagnosed PD vs. clinical assessment) make comparisons less straightforward, our pilot data are inconsistent with the hypothesis that Lancaster Amish people have a strikingly higher than expected prevalence of PD.

Because of issues such as health care access and social standards and the fact that many PD signs (e.g., hunchedover posture and slowness of movement) can be mistaken as part of normal aging, PD is often underdiagnosed. This 


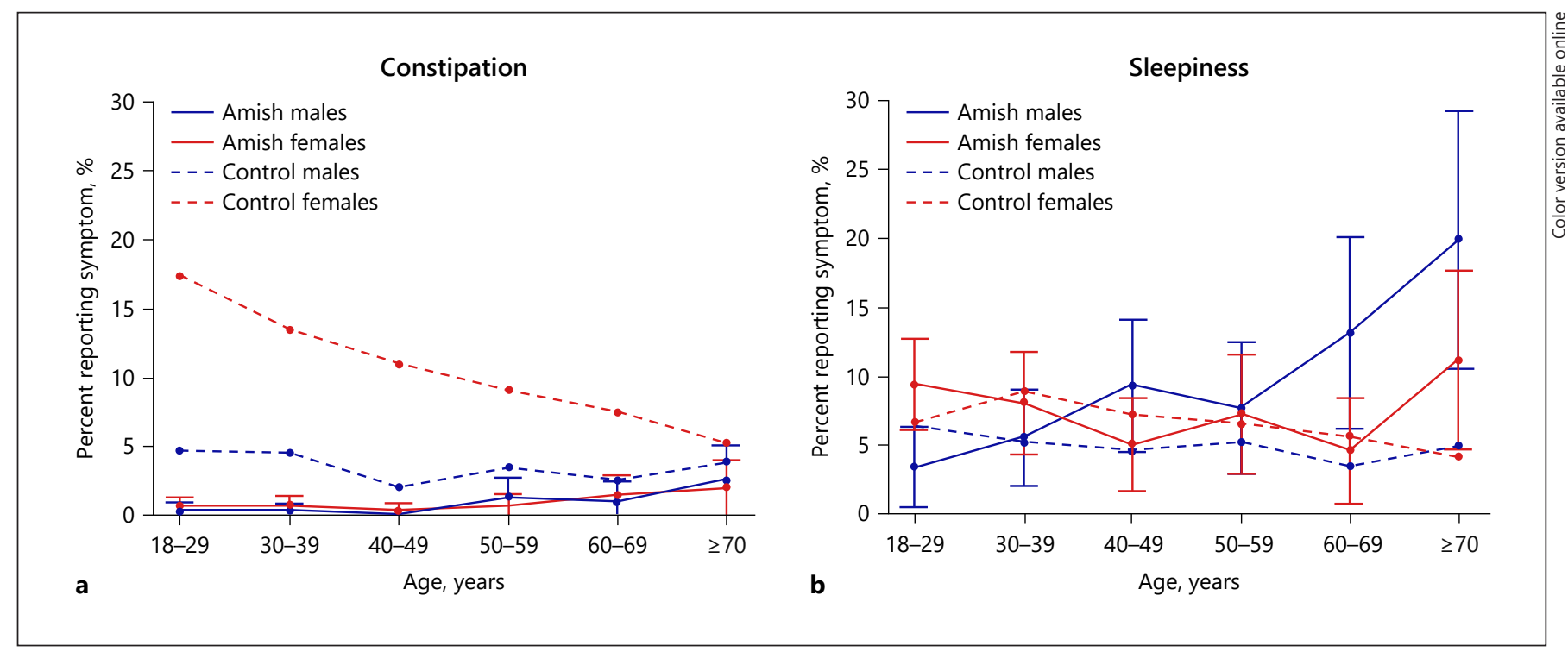

Fig. 1. Prevalence of the nonmotor symptoms of constipation (a) and sleepiness (b) reported in the Amish and the National Health and Nutrition Examination Survey, examination cycle 2005-2008 by age group (NHANES data, as reported in Chen et al. [17]). Error bars represent SD of the mean.

has motivated efforts to identify mild parkinsonian signs (MPS) without clinical diagnoses of PD in the different communities. Indeed, these efforts yield high prevalence of MPS ranging from 15 to $40 \%$ in community-dwelling older people [20-22]. In a recent study in northern Manhattan in New York City [23], Louis et al. [19] found that $25.1 \%$ of 1,866 community-dwelling older people $\geq 65$ years without PD diagnosis display MPS based on any abnormality in an abbreviated version of the Unified PD Rating Scale-Part III motor exams (parkinsonian score 1 out of a total score of 40). In the Missouri Amish without a clinical PD diagnosis, Racette et al. [7] reported that $24 \%$ of 262 participants $\geq 60$ years, and $44 \%$ MPS of 130 participants $\geq 70$, displayed MPS as defined by Unified PD Rating Scale-Part III motor exams $>9$ out of a total score of 108. In our study, 19.1\% of 204 Lancaster Amish $\geq 70$ years answered yes to one of the 9 items of the motor questionnaire developed by the PD Epidemiology Research Group to screen for PD symptoms. Despite methodological differences, our estimate based on motor symptom was comparable with those estimated in a cosmopolitan area of a neighboring state [19], but lower than that from the Missouri Amish [7].

Current detection of PD (both clinical PD and/or MPS) relies on the presence of cardinal motor signs (e.g., tremor at rest, bradykinesia, and rigidity) that often are not evident until significant nigral dopaminergic neurons have been lost $[24,25]$. Because extranigral pathology is also noted and may occur prior to classic nigral pathology [1], nonmotor symptoms often occur prior to the onset of typical motor symptoms $[12,13]$, are proposed to screen for premotor PD [26], and should be integrated part of identifying MPS [27]. This is first study that included nonmotor symptoms in an Amish community study, but for convenience we only included 2 simple nonspecific questions. We did not find higher prevalence of low bowel movement frequency or excessive daytime sleepiness in this community when compared with that of the United States' general population as we previously reported using recent NHANES data [17].

The self-reported infrequent bowel movements in Lancaster Amish were 0.7\%, lower than the 3.7\% reported by NHANES participants [17]. The data are preliminary, but if confirmed, may be explained by multiple possibilities. First, the Amish have a generally active lifestyle (e.g., farming and manual labor) that may decrease constipation [14]. Second, it is possible that this reflects the population's dietary habits or microbiome composition [14]. Third, there may be cultural sensitivity to reporting these symptoms [14]. Fourth, it is also possible that this reflects a specific trait in this relatively genetically isolated population. The self-reported sleepiness in our older $(>70$ years) Amish population seemed to be higher than that in the general population. It is possible that this finding, 
again, related to the Amish-specific lifestyles or behaviors of Amish, but the data are too preliminary to make inferences. It is also important to note that both constipation and sleepiness are not specific for $\mathrm{PD}$, and reporting errors are likely. Future studies should include assessment of more sensitive or specific PD prodromal symptoms such as sense of smell tests and screening questions for REM sleep behavior disorder.

The major strengths of our report include the relatively large sample size, unique Amish population, and a relatively high participation rate of $70 \%$. We do not have data recording why an individual chose not to participate, but the relatively high rate of participation might mitigate concerns about selection bias. Major limitations are the lack of validation of self-reported PD diagnosis, a lack of face-to-face examination of PD-related motor symptoms, and no ascertainment of other specific nonmotor symptoms such as olfaction and REM behavioral disorders. The responses may have been understated considering the cultural attributes of the Amish (stoicism, gratitude, and uncomplaining). It is also possible that Amish individuals with PD were less likely to participate in our survey.

In summary, this pilot study did not find substantially higher than expected prevalence of self-reported PD diagnosis and related motor symptoms in the Lancaster County Amish community as we initially hypothesized based on a previous report on Missouri Amish. Future studies that employ more rigorous procedures for PD case identification and more $\mathrm{PD}$-specific preclinical symptoms/tests are needed to determine the potential differences and similarities among different Amish populations having different founder histories and between Amish and other non-Amish populations. Such efforts may establish if apparent PD differences across populations are a consequence of differences in research methodology or whether they are due to genetic or lifestyle differences in PD risk factors between communities.

\section{Statement of Ethics}

The Amish Wellness Study that was the source of these data was approved by the University of Maryland Institutional Review Board, with all procedures performed in accord with the Helsinki Declaration of 1975. Only individuals aged 18 years and older were eligible for enrollment, and each signed a consent form after being informed of the study and agreeing to participate. The confidentiality of each individual was insured by anonymizing the data after collection. There was no physical risk to any individual due to participation in the study.

\section{Conflict of Interest Statement}

The authors have no financial or other conflicts of interest to report regarding any aspects of the current study.

\section{Funding Sources}

This work was supported in part by NIH Grant K18 MH093940 to the University of Maryland and Grants NS060722 and NS082151 to Penn State University.

\section{Author Contributions}

The following are the contributions of each author using the following criteria: Research project: 1A: conception, 1B: organization, 1C: execution. Data and statistical analysis: 2A: design, 2B: execution, 2C: review and critique. Manuscript preparation: 3A: writing the first draft, 3B: review and critique. Michael D.F. Goldenberg: 1B, 1C, 2B, 2C, 3A, 3B. Xuemei Huang: 1A, 1B, 1C, 2A, 2C, 3A, 3B. Honglei Chen: 1A, 1B, 1C, 2A, 2B, 2C, 3B. Lan Kong: 1C, 2A, 2B, 2C, 3B. Teodor T. Postolache: 1A, 2A, 2B, 2C, 3B. John W. Stiller: 1A, 2A, 2B, 2C, 3B. Katherine A. Ryan: 1C, 2B, 3B. Mary Pavlovich: 2B, 2C, 3B. Toni I. Pollin: 1A, 1B, 1C, 2A, 2B, 2C, 3B. Alan R. Shuldiner: 1A, 1B, 1C, 2A, 2B, 2C, 3B. Richard B. Mailman: 1A, 3B. Braxton D. Mitchell: 1A, 1B, 1C, 2A, 2B, 2C, 3A, 3B.

\section{References}

1 Braak H, Del Tredici K, Bratzke H, HammClement J, Sandmann-Keil D, Rüb U. Staging of the intracerebral inclusion body pathology associated with idiopathic Parkinson's disease (preclinical and clinical stages). J Neurol. 2002 Oct;249(Suppl 3):III/1-5.

2 Patton MA. Genetic studies in the Amish community. Ann Hum Biol. 2005;32(2):1637

3 Heutink P, Oostra BA. Gene finding in genetically isolated populations. Hum Mol Genet. 2002;11(20):2507-15.
4 Racette BA, Rundle M, Wang JC, Goate A, Saccone NL, Farrer M, et al. A multi-incident, Old-Order Amish family with PD. Neurology. 2002;58(4):568-74.

5 Lee SL, Murdock DG, McCauley JL, Bradford Y, Crunk A, McFarland L, et al. A genomewide scan in an Amish pedigree with parkinsonism. Ann Hum Genet. 2008 Sep;72(Pt 5): 621-9.
6 Cummings AC, Lee SL, McCauley JL, Jiang L, Crunk A, McFarland LL, et al. A genomewide linkage screen in the Amish with Parkinson disease points to chromosome 6. Ann Hum Genet. 2011 May;75(3):351-8.

7 Racette BA, Good LM, Kissel AM, Criswell SR, Perlmutter JS. A population-based study of parkinsonism in an Amish community. Neuroepidemiology. 2009;33(3):225-30.

8 Pringsheim T, Jette N, Frolkis A, Steeves TD. The prevalence of Parkinson's disease: a systematic review and meta-analysis. Mov Disord. 2014;29(13):1583-90. 
9 Marras C, Beck JC, Bower JH, Roberts E, Ritz B, Ross GW, et al. Prevalence of Parkinson's disease across North America. NPJ Parkinsons Dis. 2018;4:21.

10 Schoenberg BS, Anderson DW, Haerer AF. Prevalence of Parkinson's disease in the biracial population of Copiah County, Mississippi. Neurology. 1985;35(6):841-5.

11 Braak H, Del Tredici K, Rüb U, de Vos RA, Jansen Steur EN, Braak E. Staging of brain pathology related to sporadic Parkinson's disease. Neurobiol Aging. 2003;24(2):197-211.

12 Kalia LV, Kalia SK, Lang AE. Disease-modifying strategies for Parkinson's disease. Mov Disord. 2015;30(11):1442-50.

13 Schrag A, Horsfall L, Walters K, Noyce A, Petersen I. Prediagnostic presentations of Parkinson's disease in primary care: a case-control study. Lancet Neurol. 2015 Jan;14(1):5764.

14 Kraybill DB, Johnson-Weiner KM, Nolt SM. The amish. Baltimore, MD: The Johns Hopkins University Press; 2013.

15 Duarte J, Clavería LE, de Pedro-Cuesta J, Sempere AP, Coria F, Calne DB. Screening Parkinson's disease: a validated questionnaire of high specificity and sensitivity. Mov Disord. 1995;10(5):643-9.
16 Gao X, Chen H, Schwarzschild MA, Ascherio A. A prospective study of bowel movement frequency and risk of Parkinson's disease. Am J Epidemiol. 2011;174(5):546-51.

17 Chen H, Huang X, Guo X, Peddada S. Individual and joint prevalence of three nonmotor symptoms of PD in the US general population. Mov Disord. 2014 Sep;29(10):1316-9.

18 Abbott RD, Ross GW, White LR, Tanner CM, Masaki KH, Nelson JS, et al. Excessive daytime sleepiness and subsequent development of Parkinson disease. Neurology. 2005;65(9): 1442-6.

19 Louis ED, Tang MX, Schupf N, Mayeux R Functional correlates and prevalence of mild parkinsonian signs in a community population of older people. Arch Neurol. 2005 Feb; 62(2):297-302.

20 Richards M, Stern Y, Mayeux R. Subtle extrapyramidal signs can predict the development of dementia in elderly individuals. Neurology. 1993 Nov;43(11):2184-8.

21 Bennett DA, Beckett LA, Murray AM, Shannon KM, Goetz CG, Pilgrim DM, et al. Prevalence of parkinsonian signs and associated mortality in a community population of older people. N Engl J Med. 1996;334(2):71-6.
22 Wilson RS, Schneider JA, Beckett LA, Evans DA, Bennett DA. Progression of gait disorder and rigidity and risk of death in older persons. Neurology. 2002 Jun 25;58(12):1815-9.

23 Mayeux R, Marder K, Cote LJ, Denaro J, Hemenegildo N, Mejia H, et al. The frequency of idiopathic Parkinson's disease by age, ethnic group, and sex in northern Manhattan, 1988-1993. Am J Epidemiol. 1995 Oct 15; 142(8):820-7.

24 Tissingh G, Bergmans P, Booij J, Winogrodzka A, van Royen EA, Stoof JC, et al. Drugnaive patients with Parkinson's disease in Hoehn and Yahr stages I and II show a bilateral decrease in striatal dopamine transporters as revealed by [123I]beta-CIT SPECT. J Neurol. 1998;245(1):14-20.

25 Gelb DJ, Oliver E, Gilman S. Diagnostic criteria for Parkinson disease. Arch Neurol. 1999; 56(1):33-9.

26 Chen H, Burton EA, Ross GW, Huang X, Savica R, Abbott RD, et al. Research on the premotor symptoms of Parkinson's disease: clinical and etiological implications. Environ Health Perspect. 2013 Nov-Dec;121(11-12): 1245-52.

27 Louis ED, Bennett DA. Mild Parkinsonian signs: an overview of an emerging concept. Mov Disord. 2007 Sep 15;22(12):1681-8. 